\title{
Using Mobile Food Delivery Applications during the COVID-19 Pandemic: Applying the Theory of Planned Behavior to Examine Continuance Behavior
}

\author{
Van Dat Tran $(\mathbb{D}$
}

Citation: Tran, V.D. Using Mobile Food Delivery Applications during the COVID-19 Pandemic: Applying the Theory of Planned Behavior to Examine Continuance Behavior. Sustainability 2021, 13, 12066. https:/ / doi.org/10.3390/su132112066

Academic Editors: Marian Rizov and Marc A. Rosen

Received: 14 September 2021

Accepted: 20 October 2021

Published: 1 November 2021

Publisher's Note: MDPI stays neutral with regard to jurisdictional claims in published maps and institutional affiliations.

Copyright: (C) 2021 by the author. Licensee MDPI, Basel, Switzerland. This article is an open access article distributed under the terms and conditions of the Creative Commons Attribution (CC BY) license (https:// creativecommons.org/licenses/by/ $4.0 /)$.
Department of Marketing, Banking University, Ho Chi Minh 70000, Vietnam; dattv@buh.edu.vn; Tel.: +84-28-38-971-640

\begin{abstract}
COVID-19 has opened up a significant market for food delivery services in Vietnam. Based on the theory of planned behavior, subjective norms and social isolation were hypothesized to have a positive impact on behavior intention and continuance behavior. The study also aimed to determine the positive impacts of perceived food safety, food delivery, and behavioral intention on continuance behavior, while the perception of food safety and food delivery were also proposed to have direct impacts on behavioral intention. Structured equation modeling was used to evaluate data obtained from 299 respondents who were experienced in using delivery apps for ordering food. As a result, this study contributes to prior findings regarding the positive effects of the subject norm-social isolation, food delivery hygiene, perceived food safety—on behavioral intention to use mobile apps. Additionally, customers' continued usage behavior was found to be also influenced by behavioral intention, perceived food safety, and food delivery hygiene. It was concluded that these findings have significant theoretical and practical implications. This study adds to the existing debate on consumer behavior in the context of online food delivery in Vietnam and sheds light on the elements that could be used to forecast people's willingness to buy food through food delivery apps, and for how long they would continue to use them.
\end{abstract}

Keywords: social isolation; food safety; delivery cleanliness; subjective norms; continual intention

\section{Introduction}

The impact of COVID-19 on the agricultural sector is wide-ranging, causing unprecedented levels of instability in the global food supply chain, including bottlenecks in labor markets, supply chains, sourcing input materials, organizing agricultural production, processing agricultural products, transportation, logistics, etc. The world is likely to face a global food crisis, with long-term consequences not only for hundreds of millions of adults but also for the health and development of children. However, in Vietnam, the government has acted to ensure that food supplies are not interrupted and has tried to overcome the scarcity situation by promoting food production in the northern provinces. Parallel to the difficulty caused by the government's restrictions to protect people, such as not going out without unnecessary purpose, closing restaurants and stores, etc., to prevent the spread of COVID-19, there has been an explosive growth in the use of online food-ordering applications. From the point of view of service businesses, the use of an online-to-offline network for ordering and delivering food is a possibility for reviving the catering and restaurant sector, which has suffered during this pandemic [1]. The change from offline commerce to online commerce is a new type of e-commerce in which customers are drawn to a product or service online, but then finalize the purchase offline [2]. According to a recent Nielsen Vietnam survey, during the COVID-19 pandemic, up to $62 \%$ of Vietnamese customers stated that they preferred to purchase food to eat at home; hence, the number of online orders increased by approximately $10 \%$ to $30 \%$ compared with pre-pandemic times. 
There have been many works studying online ordering applications in many different national contexts. In a study conducted in Korea, the impact of food delivery apps on restaurant customer loyalty was identified. It found that usefulness, mobility, and dependability of customers had an impact on satisfaction. Moreover, mobility and dependability, in particular, had an influence on perception and commitment [3]. It suggested that instead of focusing on providing a large amount of information, food app developers should focus on increasing the mobility and trustworthiness of mobile apps [4]. While the study did not highlight its limitations, it can be seen that the demographic sample was considered as a limitation in the social research, and the study chose only certain factors that impacted on satisfaction and loyalty, but lacked other potential factors such as interaction quality, etc. [2]. Song et al. [5] investigated the impact of mobile food delivery apps' usage variables on consumer satisfaction and repurchase intent. They determined that delivery app usage characteristics had a $37.3 \%$ effect on consumers' reuse intention, with informativeness, payment, and safety being the most important aspects for enhancing reuse intention. However, because the study was conducted within a limited region, it cannot be extrapolated to the entire world's population; additionally, there are other elements that could boost customers' satisfaction with delivery applications. Other researchers [6] illustrated differences in perceptions about food delivery apps between single-person and multi-person households. According to this study, the most significant quality feature of a meal delivery app company was customer trustworthiness [6]. However, the quality measures used to evaluate food apps in this study were derived from pre-existing scales employed by scholars interested in exploring quality aspects related to general mobile app quality, rather than those particular to food delivery apps. Furthermore, the role of mobile food apps has become more significant since the global COVID-19 pandemic, which has been studied by a number of authors. During the COVID-19 pandemic in Bangladesh, Al Amin et al. [7] identified the elements that influenced customers' behavior and continued desire to utilize mobile food delivery apps. Their findings revealed that delivery cleanliness, subjective norms, attitudes, and behavioral control were all linked to behavior and continuation intent to use mobile food delivery applications, but perceived food safety was linked to behavioral intention, and social alienation to facilitating conditions [7]. However, this study was conducted during social distancing; thus, the level of relevance of safety precautions taken by each food delivery app influenced the use of specific food delivery apps. It was also not focused on elderly peoples' behavioral intention toward food delivery apps, but mainly concentrated on younger people. Pal et al. [2] studied new elements that influence consumer loyalty and satisfaction while ordering meals using mobile food delivery apps during the pandemic. They suggested that contentment, followed by food quality, were the most important predictors of loyalty in addition to satisfaction [2]. However, these data were typical of a student sample, and may have limitations in terms of relevance to other contexts or industries. Finally, Troise et al. [8] investigated the behavioral intention to utilize online food delivery services using the technology acceptance model (TAM) and the theory of planned behavior (TPB). The authors recognized that this study was one of the few studies that looked into consumers' intentions to embrace food ordering apps, and it appears to be the first to use an integrated method based on the TAM and TPB. However, they lacked the integration of other theories (such as the unified theory of acceptance and use of technology by Venkatesh et al. [9]).

Within the current, complicated situation of the COVID-19 pandemic, in Vietnam, online ordering applications such as Grab, Nowfood, Baemin, etc., promote their effectiveness. Many people in both Ha Noi and Ho Chi Minh city have used these apps to order food and household necessities because of its convenience, speed, and above all, compliance with government directives. This trend is predicted to continue, especially during this period, since people are advised to limit going out and avoid gathering in crowded places, so online shopping is chosen by many people in order to minimize the spread of the disease. Based on this knowledge, this study was conducted to analyze the underlying factors influencing customers' intention, especially behavioral intention and continual intention 
to use mobile food delivery applications based on the theory of planned behavior during the pandemic period in Vietnam. Moreover, it also suggested that practitioners design mobile food delivery application services in accordance with customers' health and other requirements. Thus, the key questions of this research are as below:

\section{- Which factors impact behavioral intention to use mobile delivery apps?}

- Which factors impact continuance behavior to use mobile delivery apps?

Additionally, this study adds to the existing literature in Vietnam. Particularly, the current study constructed and tested a theoretical model to evaluate the viability of mobile food delivery apps in the setting of the coronavirus pandemic in Vietnam. Furthermore, despite the fact that food delivery is a crucial component of mobile food delivery applications in order to satisfy customers, previous research has mostly overlooked this significant challenge. In terms of practitioners, the study has some practical implications. To convince customers that mobile food delivery apps take safety and hygienic safeguards, service providers should focus more on advertising efforts. Moreover, operators of mobile food delivery apps should pay more attention to maintaining safety when handling and delivering food, as well as communicating safety precautions to clients.

The research is structured as follows. In the following section, the definitions and previous arguments from the earlier literature are discussed. Then, data collection and analysis validation techniques are also discussed, along with analytical results. Finally, the author addresses the study's significant findings, organizational implications, and flaws, as well as some potential future research topics.

\section{Literature Review}

\subsection{Mobile Food Delivery Applications (MFDA)}

A food-ordering app can be considered as an ingenious and efficient channel that enables mobile phone users to purchase from and make payments to a variety of restaurants; the food is often delivered to customers' doorsteps without any face-to-face interaction with others [10]. According to Taylor [11], food service businesses have explored new avenues for distributing their products to consumers, and mobile food-ordering applications have grown increasingly popular in recent years. Mobile food delivery apps (mobile food delivery applications) are defined as smartphone-based applications that allow users to contact restaurants, search for food, place delivery orders, and pay bills without having to engage with restaurant staff [12]. According to a survey taken by Rakuten Insight, roughly $27 \%$ of respondents in Vietnam between the ages of 45 and 54 said they purchased food through food delivery apps once or twice a week in 2020. Additionally, 9\% of 16-24 year-olds ordered multiple times each day [13]. Moreover, Vietnamese people said they mostly bought their food using food delivery apps. Especially during the COVID-19 pandemic, customers were afraid of the crowds in restaunrants; thus, the Neilsen statistic showed that the number of online orders grew by about $10 \%$ to $30 \%$ compared to the previous year. Thus, mobile food delivery apps have been a blessing for many individuals during the COVID-19 pandemic [14] because of their benefits and outstanding functions. In particular, online food delivery apps perform a multitude of services, including giving customers a diverse range of food options, accepting orders and sending these orders to the food producer, monitoring the payment, organizing food delivery, and providing tracking tools. Additionally, the benefits of delivery apps were realized, which included the ability to find information about deliverable food in the desired region, as well as the convenience of ordering and paying for food once the application was installed on a mobile device [15]. Hence, food delivery applications have been seen as a boon to consumers' behavior, allowing individuals to consume their preferred food with appropriate nutritional information and promoting sustainable usage [10]. 


\subsection{Conceptual Framework}

Theory of Planned Behavior (TPB)

The first is Ajzen's [16] Theory of Planned Behavior (TPB), which was based on social psychology. Ajzen's TPB [16] was initially published in 1985, and has been frequently used to study the intricate connections between intentions and behaviors. The TPB model was founded on the idea that a person's desire to engage in a specific activity, as well as their capacity to choose whether or not to engage in that action (volitional aspect), drives them toward most human activities [7]. According to Ajzen [16], attitudes, subjective norms, and perceived behavioral control are three separate variables influencing behavioral intention. Hence, previous researchers have recently shown a strong interest in studying the adoption of mobile food delivery applications among customers, mostly using the theory of planned behavior [16]. Particularly, Al Amin et al. [7] used the theory of planned behavior to examine the impact of social isolation, food safety, delivery hygiene, subjective norms, dining attitudes, and behavioral control on behavioral and continued intention to use mobile food delivery applications. As a result, the current research relied on the TPB, especially the extended TPB model, to investigate which factors influenced behavioral and continued intention to use mobile food delivery applications. Firstly, the fundamental goal of the TPB model was mainly to predict intentions and behavior. Much previous research applied the TPB model in many different fields; for example, Lin et al. [17] estimated food safety behavioral intention using the theory of planned behavior; Ambak et al. [18] discovered behavioral intention to use public transportation based on the notion of planned behavior; Septiani et al. [19] discovered what elements influence online transportation service behavioral intention; and so on. Moreover, the prediction power of this proposed model is superior to the original TPB in some aspects. Firstly, this proposed model found the relationship between the variables in the TPB models and the variable "behavioral intention", while the original TPB model studies focused on separating the relationship between the variables from the model to "Behavior" and "Intention". In addition, the author did not use all three variables of the original TPB model, but rather only one main variable, which is the subjective norm, to see the relationship with other variables instead of only focusing on "intention" and "behavior", because it was proved to have significant impacts on behavioral intention [20] in many different fields such as in mobile banking [21], and especially in the food delivery apps sector $[8,22]$. In particular, Troise et al. [8] found that subjective norms had a higher impact on behavioral intentions than individuals' attitudes, and that reliability and perceptions of COVID-19 threats have various impacts. In the previous study by Heidari et al. [20], their extended TPB model was found to possess better explanatory power compared to the original TPB. Thus, in this research the author proposes the TPB model when studying the behavior and intention of using a mobile app to order food in the Vietnamese context.

\subsection{Subjective Norms, Social Isolation, Behavioral Intention, and Continuance Behavior 2.3.1. Subject Norms}

Originally, "an individual's perception that most people who are substantial to him or her think he or she should or should not imitate the behavior in inquiry" [23] was defined as the subjective norm. In recent years, it was defined relating to the support (or not) provided by social groups such as family and friends [16]. In other words, they described what was regarded as acceptable or unacceptable behavior in a given setting [11], while Bagheri [24] showed that subjective norm referred to the feeling of social pressure to perform or not execute an action. Additionally, subjective norms represent how much social pressure there is to engage or not engage in an activity [25]. Normative beliefs (NB) and motivation to comply (MC) are two aspects of the subject norm [26]. Normative beliefs are personal ideas that are accepted by certain persons or groups that determine whether or not a certain behavior is suitable [27], while the propensity to comply with the viewpoints of specific referential persons or groups is referred to as motivation to comply [28]. According to previous studies, subjective norms are critical in evaluating consumers' food intentions; for 
example, the study by Soon and Wallace [29]; Lin et ai. [30] Okumus et al. [31]; and so on. During the COVID-19 pandemic, the subjective norm has been changed in some ways.

\subsubsection{Social Isolation}

Within the next several months, the globe will face a worldwide public health catastrophe as the coronavirus pandemic 2019 (COVID-19) develops [32]. The concept of non-participation (of an individual or group) in a society's mainstream institutions was initially termed as social isolation [18]. Banerjee et al. [33] pointed out that social isolation leads to chronic melancholy and dullness, which could have negative consequences on physical and mental health if left untreated for a long time. According to Eccles [34], social isolation was described as the impartial physical separation of a human being from others, or the ability to live alone locationally and chronologically, or a situation in which a human being maintains a complete or near-complete lack of communication due to emergencies that occur in any location. Hwang et al. [35] found that older individuals were more sensitive to social isolation and loneliness because they were operationally extremely reliant on family and friends or community service assistance. Additionally, individuals' everyday lives and consuming behaviors have been altered as a result of the COVID-19 pandemic's social isolation (i.e., social distance) [36].

\subsubsection{Behavioral Intention of Using Food Delivery Apps}

Originally, Fishbein and Ajzen [21] defined that a behavioral intention was a person's perceived probability of performing a particular behavior. In terms of a dictionary definition, "To have in mind as an objective; plan to do, use, give, etc." is the definition of behavioral intention [36]. Moreover, according to Prabowo and Nugroho [37], food delivery services have developed with the introduction of numerous food delivery service providers via the internet and mobile applications. Individuals can now order food from their cellphones and have it delivered to their location quickly, and this is a trend that is expected to continue for some time, especially in the COVID-19 pandemic [38]. Following the COVID-19 outbreak and government-issued social distancing orders, food delivery services in Vietnam have exploded [14]. It is reasonable because people are restricted from going out to buy food, and food delivery apps seem to be a reasonable choice for many people to use to order food and necessities for themselves and their families. From that, the food apps made changes to consumer behavior [3]. In Vietnam, for instance, Food, Grab, Baemin, Gojeck, Shopeefood, etc., are popular mobile food delivery services. Research by Gojeck found that over 650,000 food orders were placed on the site from 2 February to 9 February 2020, and will maintain the demand in the future. Moreover, other research showed that a substantial number of Vietnamese customers used meal delivery apps at least once a week [39].

\subsubsection{Continued Behavior towards Food Delivery Apps}

Firstly, Lin et al. [17] characterized continued behavior as the intention of a customer to continue or stop using a system that relies on a past approval decision. According to Ramos et al. [39], the degree to which the perceived performance fit the initial expectations determined a consumer's repurchase intention. Particularly, Bhattacherjee and Lin [40] indicated that the individual's intentions to keep using the technical product/service were analogous to customers' repeat purchase decisions, while continued behavior was described by Davis [41] as "the readiness to utilize the mobile app indefinitely". Moreover, Al Amin et al. [7] illustrated the continued use of food delivery apps during the COVID-19 pandemic, provided people are confident that they have the necessary information, tools, and abilities to safely order food online during the COVID-19 pandemic. Additionally, every delivery comes with written unpacking instructions in the receiving package so that clients may take precautions to avoid being infected with the virus [42]. In Vietnam, Nam and An [43] conducted a study to explore how these factors, namely effort expectancy, habit, social influence, facilitating condition, hedonic motivation, price-saving orientation, 
perceived task-technology fit, confirmation, and satisfaction could have impacts on continued behavioral intention to use food delivery apps. However, this research focused on a certain population, which was the millennial group.

\subsection{Perception Food Safety and Food Delivery Hygiene \\ 2.4.1. Food Safety Concerns}

Customers' perceived food safety concerns relate to their level of concern about the safety of packaged food, food safety procedures, and food hygiene [7]. Hsu [44] described "food safety concern" as "customer worry over the quality of packaged foods, food ingredients, and environmental toxins that may endanger their physical health". He also showed that customers were growing more concerned about food safety, with an emphasis on the manufacturing process, food processing quality, and food additives [44]. Hence, as a result, the customers' need for understanding food safety and manufacturing processes is growing [45]. Additionally, Worsfold [46] indicated that a customer survey conducted by Kimberley Clark Professional found that around $84 \%$ of respondents prioritized food safety over meal quality and price, and that they would not return to a restaurant they deemed unsanitary. As a consequence, despite the enactment of strict food safety regulations, food safety in Vietnam has been a national problem that affects the physical and psychological health of Vietnamese residents; food ordering apps may be able to assist businesses in keeping food safety procedures [7]. Consumer concerns about food safety should be given attention by food service providers because they have the potential to affect the usage of their services [46].

\subsubsection{Food Delivery Hygiene}

Customers' changing behaviors as a result of the COVID-19 pandemic have forced the food delivery industry into a new race in which health and hygiene take precedence. Thus, consumers desire assurance that MFDAs deliver foods in a safe and hygienic manner [7]. To better understand the term "food delivery hygiene", Al Amin et al. [7] defined this term relating to the deliveryman's ability to keep food delivery services safe and clean. In the study by Chandrasekhar et al. [47], they showed that the most typical problem was not only the lack of hygiene in the kitchen, but also in the delivering stages. To address the issue in the kitchen, restaurants will be inspected to determine the quality of the food served as well as whether or not they are keeping proper hygiene and sanitation [7]. Concerning issues from deliverymen, quality managers maintaining the hygienic practices of their delivery boys is very important for their daily orders [35]. As a result, when customers are enthusiastic about the cleanliness techniques used by food delivery services, they are more likely to use online delivery apps.

\subsection{Hypothesis}

Many previous studies have found a link between subjective norms and attitudes and behavioral intentions. In the theory of planned behavior, Ajzen [16] examined behavioral, normative, and control beliefs, which seem to be antecedent variables of attitudes, subjective norms, and perceived behavioral control. Scalco et al. [48] found that purchasing attitude was formed in social networks or online applications, and was derived from social norms. Attitude was a salient factor in a socio-psychology model [49]. Particularly, the study by Burhanuddin [50] also concluded that intention was derived from attitude, subjective norms, and perceived behavior control, while according to Gagah [51], the perception of an application user towards the application's usefulness affected the user's attitude toward and intention to use food delivery apps in Indonesia. The study by ElGayar et al. [52] illustrated that when social influence was activated, it was also a strong predictor of the individual's behavioral intention [53]. In mobile food delivery services, numerous studies found that subjective norms significantly influenced behavioral intention and actual behavior $[7,24]$. They indicated that customers are said to be more likely to utilize meal delivery apps if their morals, beliefs, or practices align with their behavior [7]. 
However, the complicated spread of the COVID-19 pandemic in Vietnam is very different from that in Western countries, which has more or less changed the behavioral intentions of Vietnamese people towards the use of food-ordering software on their mobile phones. In addition, the prior research in Western countries related to the subjective norm was definitely different to that in Vietnam, because of the influence from cultural determinants, which make Vietname significantly different from the other countries. Therefore, this study hypothesized the relationship between subjective norms and behavioral intention in the Vietnam scenario. On the other hand, other studies found that the subjective norm also has an impact on continued behavior [31] and so on. Particularly, millennial consumers' purchasing decisions were frequently influenced by the opinions of others, particularly those perceived to be significant or influential to them [43]. Additionally, Lee et al. [54] also found that behavior had the greatest impact on continued use intention for food delivery apps, followed by performance expectations and social influence. Therefore, not mainly focusing on the other variables predicting continued behavior, this study found a relationship between subjective norms and continued behavior in the context of food delivery in Vietnam. The author proposed two hypotheses, as given below:

Hypothesis 1 (H1). Subjective norms have a positive impact on behavioral intentions to use mobile food delivery applications.

Hypothesis 9 (H9). Subjective norms have a positive impact on continuance behavior to use mobile food delivery applications.

At the peak of the COVID-19 outbreak, Vietnam's economic hub, Ho Chi Minh City, went into lockdown for two weeks in the hopes of containing the country's worst COVID19 virus outbreak. Individuals' everyday routines and consuming habits changed as a result of the COVID-19 pandemic's social isolation [7]. People who are socially isolated or quarantined tend to focus on their daily intake and must take special precautions with their food consumption. Thus, social isolation or distancing can lead to the use of mobile food delivery apps, as delivery services provide an effective way of bonding socially while being physically isolated [55]. According to a study published in 2021 by Al Amin et al. [7], there was a link between social isolation and behavioral intentions, as well as continued use of mobile delivery apps. According to Al Amin et al. [7], social isolation may change to varying degrees based on the severity of the COVID-19 outbreak in various nations, which may forecast how social isolation affects behavioral intention. This study was carried out in Bangladesh at the start of the COVID-19 pandemic's two-month duration; whereas the present study was taken in Vietnam during the peak of the COVID-19 pandemic, which might explore new findings. With regard to other fields, Chiu and Wang [56] discovered a significant link between social isolation and behavioral intentions in an e-learning context. Furthermore, some research found that situational circumstances may influence customers behavioral intentions and actual use [57]. As a result, it is critical to examine how social isolation affects behavioral intentions as well as continued behavior to utilize and use mobile delivery services during the COVID-19 pandemic. Hence, the following hypotheses are proposed:

Hypothesis 2 (H2). Social isolation has a positive impact on behavioral intentions to use mobile food delivery applications.

Hypothesis $\mathbf{8}$ (H8). Social isolation has a positive impact on continuance behavior to use mobile food delivery applications.

Despite the social distance, delivery workers have been crucial in keeping the Saigonese people nourished; however, they also are worried about infection at the country's COVID19 center. According to Pal et al. [2], mobile delivery providers have faced particular challenges as a result of the disease outbreak, such as preserving proper hygiene, requiring 
shipping agents to take extra precautions such as face masks, and stimulating consumers to make digital payments in order to reduce physical interaction. Many delivery workers resorted to wearing two masks and keeping a small hand sanitizer bottle in their jacket, as well as putting a bottle of alcohol in their motorbike trunk before leaving home [58]. In addition, washing and disinfecting the delivery bags and containers, and checking the body temperature of the delivery workers during their shifts were also practical ways to reduce the risk [58]. There are not many studies directly focusing on the positive effect of food delivery hygiene on behavioral intention and continued behavior. Al Amin [7] firstly confirmed in Bangladesh that delivery hygiene is essential to continued behavior, such that the customers tend to continue to use food delivery apps. Through behavioral intention, food delivery hygiene also anticipated users' continued behavior. However, in Vietnam or other countries, there is no research on this direct correlation. As a result, when customers are positive about the hygiene methods used by food delivery boys, they are more inclined to endorse the usage of food delivery services during the COVID-19 outbreak. Hence, the following hypotheses are proposed, as below:

Hypothesis 3 (H3). Food delivery hygiene has a positive impact on behavioral intentions to use mobile food delivery applications.

Hypothesis 7 (H7). Food delivery hygiene has a positive impact on continuance behavior to use mobile food delivery applications.

As more value is placed on quality of life and well-being, public concerns about food safety have become more prominent [59]. Especially in the COVID-19 outbreak context, people have found food safety concerns to be of paramount importance, as it affects the intention to consume products through food delivery apps [60]. Moreover, food safety risk perceptions have been researched in a number of countries [61]. Sim et al. [61] found that when consumers perceived a food safety risk, they frequently employed buying strategies to mitigate risk, such as stopping or reducing purchases of the offending product. Moreover, Al Amin et al. [7] showed that perceptions related to food safety concerns positively influenced behavioral intention towards use during the COVID-19 pandemic. In particular, customers have become more concerned about food safety, with an emphasis on the manufacturing process, food processing quality, and food additives [44]. Asian perceptions of safety concerns, especially in Vietnam, were quite different from those of Western people, in which food safety inspections decreased and food safety violations increased [62]. However, Wessells and Anderson [63] argued that food consumption might be reduced due to the customer's perceived food safety concerns. Additionally, Al Amin [7] found for the relationship between food safety and continued behavior. If customers perceived food delivery apps' service as safe, they were more likely to purchase foods. As a result, the author proposed the following hypothesis.

Hypothesis 4 (H4). Perception of food safety has a positive impact on behavioral intention to use mobile food delivery applications.

Hypothesis 6 (H6). Perception of food safety has a positive impact on continuance behavior to use mobile food delivery applications.

Food service companies and customers have embraced food delivery applications as an emergent form of online-to-offline mobile computing [64]. According to Zhao et al. [64], satisfaction was the most significant factor, and perceived task-technology fit, trust, performance expectancy, social influence, and confirmation have direct or indirect positive impacts on users' continued usage intention of food delivery apps during the COVID-19 pandemic period. Additionally, in the study developed by Al Amin et al. [7], the behavioral intention positively influenced continued intention to use food delivery applications, while Rodríguez-Ardura and Meseguer-Artola [65] also found a relationship between behavioral 
intention and continued usage in the context of using e-learning technology. Within the current COVID-19 situation, consumers have little choice, which may lead to the behavior of continuing to use mobile delivery apps during this time. Thus, the author proposed the following hypothesis:

Hypothesis 5 (H5). Behavioral intention has a positive impact on continued behavior towards mobile food delivery applications.

\section{Methodology}

\subsection{Research Framework}

The coronavirus pandemic and extensive governmental measures to combat it have resulted in an upsurge in online meal delivery [7]. Buyer penetration in the online food delivery industry is expected to reach $12.6 \%$ in 2021 [13]. Furthermore, because of the proliferation of COVID-19, revenue in the food ordering market is expected to reach USD 376 million in 2021 [13]. Previously, many authors have emphasized factors impacting on behavioral intention as well as continued behavior towards food delivery apps. For example, the study by Al Amin [7] combined TAM and TPB models to find out how factors belonging to these models influenced behavioral intention and continued behavior. However, this study was conducted during social distaning and focused on a certain population, impacting the common method variance (CMV), which were the key limitationa of the study. Moreover, Troise et al. [8] also discovered that combining the TAM and the TPB resulted in a reliable and valid model. It could be used to figure out what people want from online meal delivery services. A disadvantage of the study by Troise et al. [8] was the lack of previous studies on this subject for comparison. Thus, the study model was built based on the performed evaluation of the relevant literature using the TPB model, in which the essential components and their connections were specified (see Figure 1). This study postulated the impact of social isolation, subjective norms, food safety, and delivery hygiene on behavioral and continued intention to use mobile food delivery apps. Additionally, the author discussed whether there was a relationship between behavioral intention and continued intention in the Vietnam context.

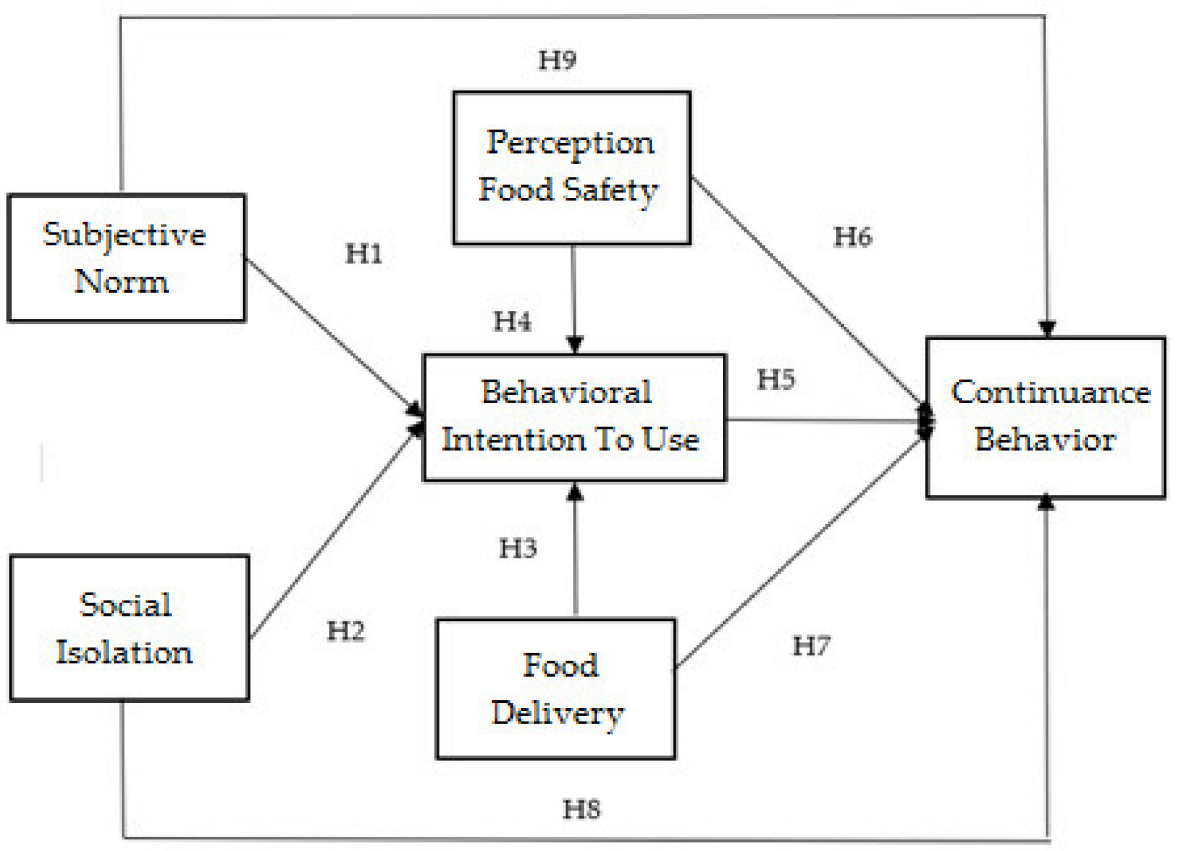

Figure 1. Research model. 


\subsection{Procedure}

The authors performed an online survey to gather information due to the less expensive cost and greater speed [66]. Furthermore, this method of data collection was appropriate for avoiding crowds and preventing virus dissemination during the time Vietnam was at the peak of the COVID-19 pandemic. Online tools such as Facebook, Zalo, and emails were used to send the survey to the potential participants. Because the total number of daily online food orders in Ho Chi Minh City was six times that of Hanoi as of 2019, the study area was placed there. Consumers aged 18 and above who purchased food using mobile delivery apps in any frequency, such as Now, Grab, Tiki, and others were the target audience for this study. Furthermore, the authors concentrated on the 18-31-year-old age group, which accounted for more than $20 \%$ of all Internet users [67] and accounted for the largest proportion of people ordering food through delivery apps in 2020. Additionally, before the real survey, a pilot test with a small sample of around 10 respondents was conducted. Pretesting has been generally useful in obtaining a better understanding of how and why specific questions might not work as anticipated, because it helps discover problematic questions [68]. Experts were asked to assess the questionnaire's applicability, logic, and usability, which culminated in language and item sequence modifications.

\subsection{Questionnaire Design}

A questionnaire was constructed with 2 parts (demographic characteristics and measurement items). The model's scales of variables were established based on prior papers. In the 1st part, respondents were asked to provide personal characteristics such as gender, age, occupation, income, education, and the mobile delivery applications they regularly use. In the measurement items part, there were 6 sub-parts, including subjective norms, social isolation, perception of food safety, behavioral intentions to use, food delivery hygiene, and continued behavior. In this section, a five-point Likert scale ranging from 1 (strongly disagree) to 5 (strongly agree) was used. Food delivery hygiene was adopted from Auad et al. [69], while subjective standards were adapted from Liang and Lim [70] and Adam et al. [71]. Additionally, social isolation was adapted from Chiu and Wang [56]. Wang and Tsai [21] and AI Amin [7] were used to adjust perception of food safety, while Venkatesh et al. [9] were used to adapt behavioral intention to use. Moreover, continued behavior was adapted from Alalwan, 2020 [12], and Al Amin [7], modified with 4 items.

The questionnaire can be found through the following link: https:/ / forms.gle/Wa1 WpVfv3YksZuRt8 (accessed on 15 August 2021).

\subsection{Demographic Statistics}

The questionnaire was distributed to 390 Vietnamese users of mobile delivery apps via an online survey in which the research objectives were explained. In addition to posting the survey on Facebook, the target sample received an e-mail and Zalo messages explaining the research's goal and inviting each user to take part in the research survey. Respondents were notified numerous times through online contacts and e-mails. There were 320 online surveys given to Vietnam mobile delivery apps users, of which 299 were valid answers. The study by Hair et al. [72] was used to determine the sample size. Furthermore, the author conducted a study of the mobile delivery apps that the survey participants utilized, and the results reveal that Grab and Delivery Now were the two most popular brands in Vietnam. Moreover, within age groups, most of respondents were in the group below 40 years old, and the largest age group was 20-30 years old. Additionally, most of them were students (28\%) and worked for educational institutions (27\%). For the demographic information, see Table 1. 
Table 1. Demographic profile.

\begin{tabular}{|c|c|c|}
\hline Category & $\begin{array}{l}\text { Number of } \\
\text { Respondents }\end{array}$ & Percentage \\
\hline \multicolumn{3}{|l|}{ Gender } \\
\hline Male & 140 & $47 \%$ \\
\hline Female & 159 & $53 \%$ \\
\hline \multicolumn{3}{|l|}{ Age } \\
\hline Less than 20 & 31 & $10 \%$ \\
\hline $20-30$ & 109 & $37 \%$ \\
\hline $30-40$ & 80 & $27 \%$ \\
\hline $40-50$ & 45 & $15 \%$ \\
\hline $50-60$ & 24 & $8 \%$ \\
\hline Above 60 & 10 & $3 \%$ \\
\hline \multicolumn{3}{|l|}{ Occupation } \\
\hline Student & 85 & $28 \%$ \\
\hline Financial & 29 & $10 \%$ \\
\hline Education & 80 & $27 \%$ \\
\hline Government & 30 & $10 \%$ \\
\hline Media & 59 & $20 \%$ \\
\hline Others & 16 & $5 \%$ \\
\hline \multicolumn{3}{|l|}{ Education } \\
\hline Senior High Diploma or Below & 37 & $12 \%$ \\
\hline Associate Bachelor's Degree & 93 & $31 \%$ \\
\hline Bachelor's Degree & 119 & $40 \%$ \\
\hline Master's Degree & 40 & $14 \%$ \\
\hline PhD Degree & 10 & $3 \%$ \\
\hline
\end{tabular}

\section{Results of Research}

\subsection{Construct Reliability}

According to Taber [73], Cronbach's alpha is a measurement typically cited by authors to illustrate that tests and scales created or accepted for research projects are suitable for the purpose. The scale was found to be reliable with a Cronbach's alpha reliability coefficient greater than 0.7 [74]. The Cronbach's alpha indexed the variables as below: subjective norms $=0.889$, social isolation $=0.774$, perception of food safety $=0.847$, food delivery hygiene $=0.744$, behavioral intentions to use $=0.8847$, and continued behavior $=0.937$. The results show that all of Cronbach's alpha coefficients $>0.7$, and the Corrected Item-Total Correlation $>0.4$. As a result, the subjective variables scale was trustworthy.

\subsection{Confirmatory Factor Analysis (CFA)}

According to Brown [75], confirmatory factor analysis (CFA) was used after exploratory factor analysis to verify the number of underlying latent variables (factors or constructs) and the pattern of observed variable-factor correlations [76]. The main criterion for evaluating compatibility was considered the loading factor value that should be $\geq 0.50$, not be $\geq 1.00$, and must be positive [77]. The goodness-of-fit for each model was assessed by examining the chi-square statistic, the comparative fit index (CFI), and the root mean square error of approximation (RMSEA). NFI, IFI, and CFI were greater than 0.90 [77], while the GFI and AGFI indexes exceeded 0.8. Chi-square/df was equal to or lower than 2 (Chisquare/df $\leq 3$ can be accepted in some cases), and RMSEA was equal to or lower than 
0.08 (RMSEA $\leq 0.05$ is excellent) [72]. The results reflect the threshold of goodness-of-fit indices and the current figures of the model. It was inevitable that the model goodness of fit was good. All fit indices satisfied the recommended values, being significant at: Chi-square $/ \mathrm{df}=1.723 ; \mathrm{GFI}=0.925 ; \mathrm{AGFI}=0.896 ; \mathrm{CFI}=0.969 ; \mathrm{RMSEM}=0.049 ; \mathrm{TLI}=0.961$ (Table 2).

Table 2. Confirmatory factor analysis.

\begin{tabular}{|c|c|c|c|}
\hline Measure & Threshold & $\begin{array}{l}\text { Present Study } \\
\text { Results }\end{array}$ & Source \\
\hline Chi-square/df (cmin/df) & $\begin{array}{l}\leq 2 \text { good; } \\
\leq 3 \text { sometimes } \\
\text { permissible }\end{array}$ & 1.723 & Hair et al. [78] \\
\hline $\begin{array}{l}\text { Goodness of fit index } \\
\text { (GFI) }\end{array}$ & $\begin{array}{c}\geq 0.9 \text { acceptable } ; \geq 0.8 \\
\text { marginal }\end{array}$ & 0.925 & Hair et al. [78] \\
\hline $\begin{array}{l}\text { Adjusted goodness of fit } \\
\text { index (AGFI) }\end{array}$ & $\geq 0.8$ & 0.896 & Hair et al. [78] \\
\hline $\begin{array}{l}\text { Comparative fit index } \\
(\mathrm{CFI})\end{array}$ & $\begin{array}{l}\geq 0.95 \text { great } ; \geq 0.90 \\
\quad \text { traditional; } \\
\geq 0.80 \text { sometimes } \\
\text { permissible }\end{array}$ & 0.969 & Hair et al. [78] \\
\hline $\begin{array}{c}\text { Root mean squared error } \\
\text { of approximation } \\
\text { (RMSEM) }\end{array}$ & $\begin{array}{l}\leq 0.05 \text { good } ; \leq 0.08 \\
\text { moderate }\end{array}$ & 0.049 & Hair et al. [78] \\
\hline Tucker-Lewis Index (TLI) & $\geq 0.90$ & 0.961 & Hair et al. [78] \\
\hline
\end{tabular}

The constructs and measurement items can be found in Table 3.

The prior step checked reliability; it was then followed by a convergent validity check. The following indicated the convergent validity of each construct. Hair et al. [77] suggested that the AVE value should be more than 0.5 and the factor loadings of each item should be greater than 0.7. Firstly, all factor loadings, ranging from 0.695 to 0.940 , were high relative to 0.5. Secondly, AVEs from 0.505 to 0.787 were greater than 0.5 . With factor loadings greater than 0.5 and AVE high relative to 0.5 , all constructs in this study can be confirmed as having convergent validity (Table 4).

Table 3. The constructs and measurement items.

\begin{tabular}{|c|c|c|c|}
\hline Construct & Items & Measures & $\begin{array}{l}\text { Supporting } \\
\text { References }\end{array}$ \\
\hline \multirow{4}{*}{ Food delivery hygiene } & FDH1 & $\begin{array}{l}\text { If the food delivery boy in the COVID-19 pandemic } \\
\text { dresses hand gloves, I am reassured. }\end{array}$ & \multirow{4}{*}{ Auad et al. [69] } \\
\hline & FDH2 & $\begin{array}{l}\text { If the food delivery boy in the COVID-19 pandemic } \\
\text { wears a face mask, I am reassured. }\end{array}$ & \\
\hline & FDH3 & $\begin{array}{l}\text { In COVID-19 pandemic, I am reassured that the food } \\
\text { delivery boy will wear a hair covering; a cap is an } \\
\text { example }\end{array}$ & \\
\hline & FDH4 & $\begin{array}{l}\text { When the delivery man maintains overall hygiene } \\
\text { precautions for the COVID-19 pandemic, I feel } \\
\text { reassured. }\end{array}$ & \\
\hline \multirow{3}{*}{ Subjective norms } & SN1 & $\begin{array}{l}\text { During the COVID-19 pandemic, I suppose my friends } \\
\text { and relatives are acceptable with my ordering food } \\
\text { through the food delivery apps. }\end{array}$ & \multirow{2}{*}{$\begin{array}{l}\text { Liang and Lim } \\
{[70]}\end{array}$} \\
\hline & SN2 & $\begin{array}{l}\text { During the COVID-19 pandemic, my friends and family } \\
\text { encourage my decision to get food through the food } \\
\text { delivery apps. }\end{array}$ & \\
\hline & SN3 & $\begin{array}{l}\text { During the physical distancing causing by COVID-19 } \\
\text { pandemic, I suppose my friends and relatives order } \\
\text { food via food delivery apps. }\end{array}$ & Adam et al. [71] \\
\hline
\end{tabular}


Table 3. Cont.

\begin{tabular}{|c|c|c|c|}
\hline Construct & Items & Measures & $\begin{array}{l}\text { Supporting } \\
\text { References }\end{array}$ \\
\hline \multirow{3}{*}{ Social isolation } & SI1 & $\begin{array}{l}\text { During COVID-19, I suppose food delivery apps } \\
\text { expanding chances for foods evaluations instead of the } \\
\text { face-to-face interaction. }\end{array}$ & \multirow{3}{*}{$\begin{array}{l}\text { Chiu and Wang } \\
\text { [56] }\end{array}$} \\
\hline & SI2 & $\begin{array}{l}\text { During COVID-19, I am persuaded using the food } \\
\text { delivery apps to purchase foods, for avoiding } \\
\text { face-to-face encounters. }\end{array}$ & \\
\hline & SI3 & $\begin{array}{l}\text { Even if I am constrained during the COVID-19 term, I } \\
\text { believe food delivery apps will satisfy my expectation. }\end{array}$ & \\
\hline \multirow{3}{*}{$\begin{array}{l}\text { Perception of food } \\
\text { safety }\end{array}$} & PFS1 & $\begin{array}{l}\text { In the COVID-19 pandemic, I feel safe when ordering } \\
\text { foods via food delivery apps. }\end{array}$ & \multirow{2}{*}{$\begin{array}{l}\text { Wang and Tsai } \\
{[21]}\end{array}$} \\
\hline & PFS2 & $\begin{array}{l}\text { In the COVID-19 pandemic, I feel sanitary (i.e., no viral } \\
\text { infections) when ordering foods via food delivery apps. }\end{array}$ & \\
\hline & PFS3 & $\begin{array}{l}\text { In the COVID-19 pandemic, I feel hygienic (i.e., no } \\
\text { pathogens or mosquitoes). }\end{array}$ & AI Amin et al. \\
\hline \multirow{3}{*}{$\begin{array}{l}\text { Behavioral intention to } \\
\text { use }\end{array}$} & BIU1 & $\begin{array}{l}\text { I intend to recommend for my friends and relatives } \\
\text { using the food delivery apps in the future. }\end{array}$ & \multirow{2}{*}{$\begin{array}{l}\text { Venkatesh et al. } \\
\quad[9]\end{array}$} \\
\hline & BIU2 & $\begin{array}{l}\text { I intend to make every effort to use the food delivery } \\
\text { apps in my daily life. }\end{array}$ & \\
\hline & BIU3 & $\begin{array}{l}\text { I intend to utilize the food delivery apps on a special } \\
\text { events (birthday party as an example). }\end{array}$ & $\begin{array}{c}\text { Author } \\
\text { proposed }\end{array}$ \\
\hline \multirow{4}{*}{ Continued behavior } & CB1 & If I had the chance, I will order food online. & $\begin{array}{l}\text { Alalwan et al. } \\
{[12]}\end{array}$ \\
\hline & CB2 & $\begin{array}{l}\text { I expect to continue using the meal delivery apps to } \\
\text { place my orders. }\end{array}$ & $\begin{array}{l}\text { Alalwan et al. } \\
{[12]}\end{array}$ \\
\hline & CB3 & In the future, I will use the food delivery apps & $\mathrm{Al}$ Amin [7] \\
\hline & CB4 & $\begin{array}{l}\text { I maintain to utilize the food delivery apps on a regular } \\
\text { basis. }\end{array}$ & $\mathrm{Al} \mathrm{Amin}[7]$ \\
\hline
\end{tabular}

Table 4. Confirmatory factor analysis (CFA) fitting indices.

\begin{tabular}{|c|c|c|c|c|}
\hline Constructs & Estimate & Cronbach & CR & AVE \\
\hline Subjective norm & & 0.889 & 0.893 & 0.736 \\
\hline SN1 & 0.812 & & & \\
\hline SN2 & 0.876 & & & \\
\hline SN3 & 0.884 & & & \\
\hline Social isolation & & 0.774 & 0.774 & 0.533 \\
\hline SI1 & 0.695 & & & \\
\hline SI2 & 0.766 & & & \\
\hline SI3 & 0.729 & & & \\
\hline Perception food safety & & 0.847 & 0.850 & 0.654 \\
\hline PFS1 & 0.798 & & & \\
\hline PFS2 & 0.768 & & & \\
\hline PFS3 & 0.858 & & & \\
\hline Food delivery hygiene & & 0.744 & 0.753 & 0.505 \\
\hline FDH1 & 0.755 & & & \\
\hline FDH2 & 0.663 & & & \\
\hline FDH3 & 0.712 & & & \\
\hline Behavioral intention to use & & 0.847 & 0.850 & 0.655 \\
\hline BIU1 & 0.733 & & & \\
\hline BIU2 & 0.806 & & & \\
\hline BIU3 & 0.883 & & & \\
\hline Continued behavior & & 0.937 & 0.936 & 0.787 \\
\hline CB1 & 0.785 & & & \\
\hline CB2 & 0.881 & & & \\
\hline CB3 & 0.940 & & & \\
\hline
\end{tabular}




\subsection{Discriminant Validity and Correlations}

To determine discriminant validity, a comparison should be made between the value of a factor's square root of AVE and its inter-construct correlations with other factors, with the value of the square root of AVE being larger. According to Fornell and Larcker [79], if the AVE value for each variable is higher than the square of the correlation between that and any other variable, discriminant validity is achieved. Thus, structural equation modeling could be carried out once the construct validity of the variables had been established. Table 5 indicated that the lowest AVE ( 0.505 for FDH) exceeded the highest square root inter-construct correlation ( 0.787 for $\mathrm{CB})$. As a result, the discriminant validity of the measurement model was acceptable.

Table 5. Discriminant validity.

\begin{tabular}{ccccccc}
\hline & SN & SI & PFS & FDH & BIU & CB \\
\hline SN & 0.736 & & & & & \\
\hline SI & 0.365 & 0.533 & & & & \\
\hline PFS & 0.145 & 0.218 & 0.654 & & & \\
\hline FDH & 0.347 & 0.376 & 0.254 & 0.505 & & \\
\hline BIU & 0.176 & 0.193 & 0.358 & 0.269 & 0.655 & \\
\hline CB & 0.201 & 0.236 & 0.543 & 0.242 & 0.428 & 0.787 \\
\hline
\end{tabular}

\subsection{Hypothesis Testing}

Structural equation modeling (SEM) was employed to examine the relationships among the constructs in the model and its validity. The software AMOS was used to perform this data analysis. From this path diagram, it can be observed that all the statistics for the model fit were met at a good or even great degree: Chi-square $=367.445 ; \mathrm{df}=143 ; p$-value $=0.00$; Chi-square $/ \mathrm{df}=2.570 ; \mathrm{GFI}=0.879 ; \mathrm{GFI}=0.879 ; \mathrm{CFI}=0.930 ; \mathrm{RMR}=0.106$; $\mathrm{RMSEA}=0.073$ ). Normed X2/df was 1.374 [80], indicating that the research model was successful.

Data analysis indicated that the subjective norm had a significantly positive impact on behavioral intention to use mobile delivery apps ( $\beta=0.311, p<0.001)$. Thus, H1 was supported. Additionally, social isolation had significantly positive effects on behavioral intention to use mobile delivery apps ( $\beta=0.202, p<0.01)$, and so H2 was also supported in this study. This study also found a positive direct relationship between food delivery hygiene ( $\beta=0.216, p<0.01)$ and behavioral intention to use, as well as the perception of food safety $(\beta=0.350, p<0.001)$ and behavioral intention to use. Thus, $\mathrm{H} 3$ and $\mathrm{H} 4$ were also definitely supported. Moreover, behavioral intention to use $(\beta=0.350, p<0.001)$, perception of food safety $(\beta=0.247, p<0.001)$, and food delivery hygiene $(\beta=0.480$, $p<0.001$ ) were found to have a significant influence on continued behavior. Hence, $\mathrm{H} 4$, $\mathrm{H} 5$, and $\mathrm{H} 6$ were also supported. On the other hand, this study did not find any effects of social isolation $(\beta=0.078)$ and subjective norm $(\beta=0.077)$ on continued behavior, thus H8 and $\mathrm{H} 9$ were unsupported (Table 6). 
Table 6. Hypothesis testing results.

\begin{tabular}{lcc}
\hline \multicolumn{1}{c}{ Hypotheses } & $\begin{array}{c}\text { Standardized Path } \\
\text { Coefficient }\end{array}$ & Result \\
\hline $\begin{array}{l}\text { H1: Subjective norm has a positive impact on behavioral intention to } \\
\text { use mobile food delivery applications }\end{array}$ & $0.311^{* * *}$ & Supported \\
\hline $\begin{array}{l}\text { H2: Social isolation has a positive impact on behavioral intention to use } \\
\text { mobile food delivery applications }\end{array}$ & $0.202^{* *}$ & Supported \\
\hline $\begin{array}{l}\text { H3: Food delivery hygiene has a positive impact on behavioral } \\
\text { intention to use mobile food delivery applications }\end{array}$ & $0.216^{* *}$ & Supported \\
\hline $\begin{array}{l}\text { H4: Perception food safety has a positive impact on behavioral } \\
\text { intention to use mobile food delivery applications }\end{array}$ & $0.350^{* * *}$ & $0.247^{* * *}$ \\
\hline H5: Behavioral intention has a positive impact on continued behavior & $0.480^{* * *}$ & Supported \\
\hline $\begin{array}{l}\text { H6: Perception of food safety has a positive impact on continued } \\
\text { behavior to use mobile food delivery applications. }\end{array}$ & $0.269^{* * *}$ \\
\hline $\begin{array}{l}\text { H7: Food delivery hygiene has a positive impact on continued } \\
\text { behavior to use mobile food delivery applications }\end{array}$ & 0.078 \\
\hline $\begin{array}{l}\text { H8: Social isolation has a positive impact on continued behavior to use } \\
\text { mobile food delivery applications }\end{array}$ & Supported \\
\hline $\begin{array}{l}\text { H9: Subjective norm has a positive impact on continued behavior to } \\
\text { use mobile food delivery applications }\end{array}$ & $0.077^{*}$ \\
\hline
\end{tabular}

Note. $N=299,{ }^{* *} p<0.01 ; * * * p<0.001$.

\section{Discussion}

In the food service business, mobile food-ordering applications are here to remain, and their popularity is only likely to rise in the coming years [11]. In the current scenario, research is focused on analyzing the impact of customers' perception of food safety, social isolation, food delivery hygiene, and subjective norms on the behavioral intention and continued behavior to use mobile food delivery apps during the COVID-19 pandemic. The majority of the hypotheses were valid, which is in line with some of the findings from the study by Al Amin et al. [7]; Taylor [11]; Troise et al. [8]; and Chiu and Wang [56]. It suggests that the subjective norm was considered one of the essential determinants predicting behavioral intention to use food ordering apps, while the subjective norm was not found to have a relationship with continued behavior, which was in the contrast to the study by $\mathrm{Al}$ Amin et al. [7]. As a consequence, using food-ordering apps, whereby all users approve and support their buying food through mobile apps, will result in a direct increase in their behavioral intention to use apps, but not affect their continued usage. Additionally, the study found that social isolation and behavioral intention were positively related, which was the same finding as that of $\mathrm{Al} \mathrm{Amin} \mathrm{et} \mathrm{al.} \mathrm{[7],} \mathrm{but} \mathrm{in} \mathrm{contrast} \mathrm{to} \mathrm{the} \mathrm{study} \mathrm{by} \mathrm{Chiu} \mathrm{and}$ Wang [56]. Chang and Wang [56] argued that customers' behavioral intentions would not be influenced by striving for social distance. However, in the context of the COVID-19 outbreak in Vietnam, through social distancing for preventing the spread of COVID-19, the customers' behavioral intention will be changed in a positive way. On the other hand, there was no relationship between social isolation and continued behavior to use mobile apps for food ordering, which is quite in contrast to the finding by Al Amin et al. [7], although it is similar to Zhang et al. [57]. When people are in social isolation during the COVID-19 pandemic, it does not mean they will continue using the food delivery apps because of some potential reasons which are listed by the authors, such as high transportation fees, considerations about food safety, etc. Furthermore, during the COVID-19 pandemic, food delivery hygiene practices by deliverymen such as wearing masks, gloves, and so on had a favorable influence on behavioral intention and continued behavior to use food delivery applications, which is consistent with Al Amin et al. [7]. The delivery staff's personal interaction with people is critical due to the fact that the novel coronavirus spreads from 
person to person [7]. In particular, it indicates that food hygiene is critical to customer retention and retention behavior, such that consumers will continue to use mobile food delivery app services and increase their behavioral intention if food suppliers can assure food hygiene in all orders. Additionally, the positive relationship between perception of food safety and behavioral intention was similar to the prior studies by Hsu et al. [44] and Al Amin et al. [7]. The more customers are likely to purchase food through food delivery apps, the more they believe the service provided by mobile food ordering apps is safe. Thus, mobile food ordering apps' service providers endorse their businesses by assuring customers that they follow appropriate safety and hygiene measures in food processing, handling, and delivery [81], while perception of food safety was not found to have any direct connection with continued behaviors, which is the same as Al Amin's [7] findings. It demonstrates that consumers who become less worried about health and sanitary procedures may disregard what is occurring inside restaurants, as well as delivery staffs' activities, in order to maintain their use of mobile apps. Moreover, the finding also contributed to the study by Al Amin et al. [7], suggesting that behavioral intention was one of the variables that might predict customers' continued use of food-ordering applications. Thus, customers are more inclined to use food-ordering apps during the pandemic, since they have restricted alternatives for purchasing restaurant items.

\section{Conclusions}

In general, COVID-19 has created a large market space for food delivery service providers in Vietnam, and this tendency will extend further when ordering food via apps becomes the norm. Thus, food delivery service providers with the deepest understanding of customer demands will be the ones to acquire solid growth. Therefore, this paper built a model to find the relationship between the following factors, namely the subjective norm, social isolation, perception of food safety, and food delivery hygiene, and their effect on behavioral intention to use and continued usage, as well as the interplay between these factors. The resulting process brought a special meaning to the service sector, especially the food-ordering applications sector. In parallel with the prior studies of Al Amin et al. [7], Taylor [11], Troise et al. [8], and Chiu and Wang [56], the author not only investigated the inheritance of previous literature but also expanded upon it. However, this outcome was not parallel with these previous findings in some aspects. One of the most notable distinctions was that this study showed no link between social isolation and continued usage of mobile apps for food ordering in the Vietnam context, which contrasted with Al Amin et al. [7] but was comparable to Zhang et al. [57]. When individuals are socially isolated due to the COVID-19 outbreak, it is unlikely that they will continue to utilize food delivery apps for a variety of reasons, including high shipping costs, concerns about food hygiene, and so on. However, if the food providers sell on food delivery apps, and deliverymen made an effort to maintain strict food hygiene, such as obeying the $5 \mathrm{~K}$ principle, ensuring no contamination of food by insects or viruses and so on, it may be effective for increasing customers' continued behavior. Moreover, during the COVID-19 outbreak in Vietnam, the study also discovered a positive relationship between social isolation and behavioral intention, which was not found in the context of e-learning from the study of Chiu and Wang [56]. It can be understood that customers' behavioral intentions will be modified in a desirable direction in the context of the COVID-19 pandemic in Vietnam through social distancing to slow the transmission of COVID-19. Hence, this study integrated situational considerations into the theory of planned behavior, which may help practitioners decide whether or not to utilize food delivery applications during COVID-19. Particularly, the study found that if consumers' morals, beliefs, or practices are consistent with their behavior while ordering delivery food through apps, they are more likely to use the same service again. Moreover, perceived food safety is not a key predictor of continued usage, suggesting that customers may disregard what is occurring inside restaurants in order to keep purchasing meals, and be less worried about safety and hygiene procedures. 


\section{Theoretical and Practical Implications}

The findings of this study have a wide range of consequences for both research and practice. Firstly, the current study created and tested a conceptual model based on the expanded theory of planned behavior [16] to assess the continued usage and behavioral intention toward mobile food delivery applications in Vietnam during the coronavirus pandemic. Moreover, the current research is one of the pioneer empirical studies in Vietnam that includes social isolation (i.e., during COVID-19 or any confined situations) as a situational variable to identify the influence on customers' behavioral and continued intention to use food delivery apps. Vietnamese behavioral intention with regard to the usage of mobile food-ordering apps has changed, experiencing a high increase in demand; according to the research by the Neilsen company, their statistics showed that up to $62 \%$ of Vietnamese customers' opined that they would like to buy food at their home [82]. However, there has been no research on customers' behavioral intention towards using mobile foodordering apps in Vietnam. This study did not confirm that social isolation influences users' continued behavior in the COVID-19 pandemic period in Vietnam, which is a new finding, because previous authors supported this positive relationship. Additionally, while COVID-19's influence on the food delivery business is critical worldwide, there are not many studies which focus on customer behavior in Southeast Asian countries, especially in Vietnam. On the other hand, practical implications were also highlighted in this study. In general, COVID-19 has created a large market space for food delivery service providers in Vietnam, and this potential will expand further when ordering food via apps becomes the norm. Food delivery service providers with the deepest understanding of customer demands will be the ones to acquire solid growth. Service providers should focus more on advertising activities to persuade customers that food delivery apps take safety and hygiene precautions because of the effects of delivery food hygiene. Moreover, online training courses to transmit the precautionary measures employed in preparing the meals may potentially be available through mobile food delivery apps. Additionally, operators should ensure a high standard of hygiene when handling and delivering products, as well as transmit safety tips to consumers. In addition, for MFDA users to refer the platforms to their friends, colleagues, or relatives would increase the subjective norm, leading to higher behavioral intention to use food delivery apps; thus, the provider should have more promotional campaigns such as price discounts, accumulated bonus points, and so on for boosting their consumption and their enthusiasm in making recommendations as well. Buyers are more likely to suggest and accept recommendations from friends and relatives when it comes to using certain food delivery apps.

\section{Limitations and Future Work}

While conducting this study, several limitations were encountered. Firstly, the data were collected in Vietnam during the COVID-19 pandemic, which limited the generalization of the study findings when compared to a typical time. As a result, future studies may recreate this study in different nations in order to generalize the results across a larger geographical area. Second, the honest reviews of customers as valuable preferences on a website because a supplier might judge inaccurately about their quality. Moreover, customers can conduct surveys hurriedly without careful consideration. In addition, this study relied on a quantitative approach, which also limited the scope of our findings. In future studies, academics should focus on qualitative and longitudinal data collection to acquire deeper insights. Furthermore, there are numerous factors that influence subjective norms. The author neglected to include belief construct as a determinant of subjective norms; consequently, future studies in the food delivery sector should include belief structure as a potential predictor of subjective norms.

Funding: This research received no external funding.

Institutional Review Board Statement: Ethical review and approval was not required for this study on human participants in accordance with the local legislation and institutional requirements. 
Informed Consent Statement: Written informed consent from the patients/participants was not required to participate in this study in accordance with the national legislation and the institutional requirements.

Data Availability Statement: The data presented in this study are available on request from the corresponding author. The data are not publicly available due to assured participant confidentiality.

Conflicts of Interest: The author declares no conflict of interest.

\section{References}

1. Fishbein, M.; Ajzen, I. Belief, Attitude, Intention, and Behavior: An Introduction to Theory and Research; Adison-Wesley: Reading, MA, USA, 1975. [CrossRef]

2. Pal, D.; Funilkul, S.; Eamsinvattana, W.; Siyal, S. Using online food delivery applications during the COVID-19 lockdown period: What drives University Students' satisfaction and loyalty? J. Foodserv. Bus. Res. 2021, 1-45. [CrossRef]

3. Ram, J.; Sun, S. Business Benefits of Online-To-Offline Ecommerce: A Theory Driven Perspective. J. Innov. Econ. 2020, 33, 135-162. [CrossRef]

4. Song, Y.E.; Jeon, S.H.; Jeon, M.S. The effect of mobile food delivery application usage factors on customer satisfaction and intention to reuse. Culin. Sci. Hosp. Res. 2017, 23, 37-47.

5. Cha, S.S.; Seo, B.K. The effect of food delivery application on Customer Loyalty in Restaurant. J. Distrib. Sci. 2020, 18, 5-12.

6. Cho, M.; Bonn, M.A.; Li, J.J. Differences in perceptions about food delivery apps between single-person and multi-person households. Int. J. Hosp. Manag. 2019, 77, 108-116. [CrossRef]

7. Al Amin, M.; Arefin, M.S.; Alam, M.R.; Ahammad, T.; Hoque, M.R. Using mobile food delivery applications during COVID-19 pandemic: An extended model of planned behavior. J. Food Prod. Mark. 2021, 27, 105-126. [CrossRef]

8. Troise, C.; O'Driscoll, A.; Tani, M.; Prisco, A. Online food delivery services and behavioural intention-A test of an integrated TAM and TPB framework. Br. Food J. 2020, 123. [CrossRef]

9. Venkatesh, V.; Thong, J.Y.L.; Xu, X. Consumer acceptance and use of information technology: Extending the unified theory of acceptance and use of technology. MIS Q. 2012, 36, 157-178. [CrossRef]

10. Chotigo, J.; Kadono, Y. Comparative Analysis of Key Factors Encouraging Food Delivery App Adoption Before and During the COVID-19 Pandemic in Thailand. Sustainability 2021, 13, 4088. [CrossRef]

11. Taylor, S., Jr. Campus dining goes mobile: Intentions of college students to adopt a mobile food-ordering app. J. Foodserv. Bus. Res. 2020, 24, 121-139. [CrossRef]

12. Alalwan, A.A. Mobile food ordering apps: An empirical study of the factors affecting customer e-satisfaction and continued intention to reuse. Int. J. Inf. Manag. 2020, 50, 28-44. [CrossRef]

13. Online Food Delivery-Vietnam I Statista Market Forecast. 2021. Available online: https://www.statista.com/outlook/dmo/ eservices/online-food-delivery/vietnam\#revenue (accessed on 16 October 2021).

14. Dich vu Giao Nhan do an Truc Tuyen Tang cao trong Mua Dich COVID-19. Available online: https://vneconomy.vn/dich-vugiao-nhan-do-an-truc-tuyen-tang-cao-trong-mua-dich-covid-19.htm (accessed on 31 August 2021).

15. Ko, H.S. A study on the eelivery app transactions and consumer protection. Law Rev. 2016, 24, 62.

16. Ajzen, I. From intentions to actions: A theory of planned behavior. In Action Control; Springer: Berlin/Heidelberg, Germany, 1985; pp. 11-39.

17. Lin, C.-Y. Social reaction toward the 2019 novel coronavirus (COVID-19). Soc. Health Behav. 2020, 3, 1. [CrossRef]

18. Ambak, K.; Kasvar, K.K.; Daniel, B.D.; Prasetijo, J.; Ghani, A.R.A. Behavioral Intention to Use Public Transport Based on Theory of Planned Behavior. In Proceedings of the MATEC Web of Conferences; EDP Sciences: Paris, France, 2016; Volume 47, p. 3008.

19. Septiani, R.; Handayani, P.W.; Azzahro, F. Factors that Affecting Behavioral Intention in Online Transportation Service: Case study of GO-JEK. Procedia Comput. Sci. 2017, 124, 504-512. [CrossRef]

20. Heidari, A.; Kolahi, M.; Behravesh, N.; Ghorbanyon, M.; Ehsanmansh, F.; Hashemolhosini, N.; Zanganeh, F. Youth and sustainable waste management: A SEM approach and extended theory of planned behavior. J. Mater. Cycles Waste Manag. 2018, 20, $2041-2053$. [CrossRef]

21. Fishbein, M.; Jaccard, J.; Davidson, A.R.; Ajzen, I.; Loken, B. Predicting and understanding family planning behaviors. In Understanding Attitudes and Predicting Social Behavior; Prentice Hall: Upper Saddle River, NJ, USA, 1980.

22. Lee, E.-Y.; Lee, S.-B.; Jeon, Y.J.J. Factors influencing the behavioral intention to use food delivery apps. Soc. Behav. Pers. Int. J. 2017, 45, 1461-1473. [CrossRef]

23. Claycomb, J.M.; Batista, P.J.; Pang, K.M.; Gu, W.; Vasale, J.J.; van Wolfswinkel, J.C.; Chaves, D.A.; Shirayama, M.; Mitani, S.; Ketting, R.F.; et al. The Argonaute CSR-1 and Its 22G-RNA Cofactors Are Required for Holocentric Chromosome Segregation. Cell 2009, 139, 123-134. [CrossRef] [PubMed]

24. Bagheri, A.; Bondori, A.; Allahyari, M.S.; Damalas, C.A. Modeling farmers' intention to use pesticides: An expanded version of the theory of planned behavior. J. Environ. Manag. 2019, 248, 109291. [CrossRef]

25. Bai, L.; Wang, M.; Gong, S. Understanding the Antecedents of Organic Food Purchases: The Important Roles of Beliefs, Subjective Norms, and Identity Expressiveness. Sustainability 2019, 11, 3045. [CrossRef]

26. Nugroho, A.; Najib, M.; Simanjuntak, M. Factors Affecting Consumer Interest In Electronic Money Usage With Theory Of Planned Behavior (TPB). J. Consum. Sci. 2018, 3, 15-27. [CrossRef] 
27. Ajzen, I. Constructing a Theory of Planned Behavior Questionnaire. 2006. Available online: http://people.umass.edu/ \{\}aizen/ pdf/tpb.measurement.pdf (accessed on 20 July 2017).

28. Fishbein, M.; Ajzen, I. Predicting and Changing Behavior: The Reasoned Action Approach; Psychology Press: New York, NY, USA, 2010.

29. Soon, J.M.; Wallace, C. Application of theory of planned behaviour in purchasing intention and consumption of Halal food. Nutr. Food Sci. 2017, 47, 635-647. [CrossRef]

30. Lin, K.-M. e-Learning continuance intention: Moderating effects of user e-learning experience. Comput. Educ. 2011, 56, 515-526. [CrossRef]

31. Okumus, B.; Bilgihan, A. Proposing a model to test smartphone users' intention to use smart applications when ordering food in restaurants. J. Hosp. Tour. Technol. 2014, 5, 31-49. [CrossRef]

32. Wabo, H.; De Kock, M.; Klausen, M.; Soderlund, U.; Beukes, N. Paleomagnetism and chronology of B-1 marginal sills of the Bushveld Complex from the eastern Kaapvaal Craton, South Africa. GFF 2015, 138, 133-151. [CrossRef]

33. Banerjee, D.; Rai, M. Social isolation in COVID-19: The impact of loneliness. Int. J. Soc. Psychiatry 2020, 66, 525-527. [CrossRef]

34. Eccles, J.S. Gender Roles and Women's Achievement-Related Decisions. Psychol. Women Q. 1987, 11, 135-172. [CrossRef]

35. Hwang, T.-J.; Rabheru, K.; Peisah, C.; Reichman, W.; Ikeda, M. Loneliness and social isolation during the COVID-19 pandemic. Int. Psychogeriatr. 2020, 32, 1217-1220. [CrossRef] [PubMed]

36. Barry, B. Social Exclusion, Social Isolation and the Distribution of Income; London School of Economics: London, UK, 1998.

37. Prabowo, G.T.; Nugroho, A. Factors that influence the attitude and behavioral intention of Indonesian users toward online food delivery service by the Go-Food application. Adv. Econ. Bus. Manag. Res. 2019, 72, 204-210.

38. Muangmee, C.; Kot, S.; Meekaewkunchorn, N.; Kassakorn, N.; Khalid, B. Factors Determining the Behavioral Intention of Using Food Delivery Apps during COVID-19 Pandemics. J. Theor. Appl. Electron. Commer. Res. 2021, 16, 1297-1310. [CrossRef]

39. Ramos, K. Factors influencing customers' continuance usage intention of food delivery apps during COVID-19 quarantine in Mexico. Br. Food J. 2021. [CrossRef]

40. Bhattacherjee, A.; Lin, C.-P. A unified model of IT continuance: Three complementary perspectives and crossover effects. Eur. J. Inf. Syst. 2015, 24, 364-373. [CrossRef]

41. Davis, F.D. Perceived usefulness, perceived ease of use, and user acceptance of information technology. MIS Q. 1989, 13, 319-340. [CrossRef]

42. Siddiqui, K. Is it Safe to Order Food Home amid Pandemic? Mostly Yes, the Business Standard. 2020. Available online: https:/ / tbsnews.net/bangladesh/health/it-safe-order-food-home-amid-pandemic-mostly-yes-120031 (accessed on 2 September 2020).

43. Nam, L.G.; An, T.; Thi, N. Factors Affecting the Continuance Intention to Use Food Delivery Apps of The Millennials in Ho Chi Minh City. Technium Soc. Sci. J. 2021, 18, 404.

44. Hsu, S.-Y.; Chang, C.-C.; Lin, T.T. An analysis of purchase intentions toward organic food on health consciousness and food safety with/under structural equation modeling. Br. Food J. 2016, 118, 200-216. [CrossRef]

45. Ureña, F.; Bernabéu, R.; Olmeda, M. Women, men and organic food: Differences in their attitudes and willingness to pay. A Spanish case study. Int. J. Consum. Stud. 2007, 32, 18-26. [CrossRef]

46. Worsfold, D. Eating out: Consumer perceptions of food safety. Int. J. Environ. Health Res. 2006, 16, 219-229. [CrossRef] [PubMed]

47. Chandrasekhar, N.; Gupta, S.; Nanda, N. Food Delivery Services and Customer Preference: A Comparative Analysis. J. Foodserv. Bus. Res. 2019, 22, 375-386. [CrossRef]

48. Scalco, A.; Noventa, S.; Sartori, R.; Ceschi, A. Predictingorganicfoodconsumption: Ameta-analyticstructural equation model based on the theory of planned behavior. Appetite 2017, 112, 235-248. [CrossRef]

49. Wang, E.S.-T.; Tsai, M.-C. Effects of the perception of traceable fresh food safety and nutrition on perceived health benefits, affective commitment, and repurchase intention. Food Qual. Prefer. 2019, 78, 103723. [CrossRef]

50. Burhanudin. Aplikasi theory of planned behavior pada intensi mahasiswa untuk berwirausaha. J. Bisnis Dan Ekon. 2015, 6, 60-72.

51. Me, Q. Food Delivery Demand Increase After COVID-19; Asia Plus Inc.: Tokyo, Japan, 2020.

52. El-Gayar, O.F.; Moran, M.; Hawkes, M. Students' acceptance of tablet PCs and implications for educational institutions. Educ. Technol. Soc. 2011, 14, 58-70.

53. Ali, F.; Nair, P.K.; Hussain, K. An assessment of students' acceptance and usage of computer supported collaborative classrooms in hospitality and tourism schools. J. Hosp. Leis. Sport Tour. Educ. 2016, 18, 51-60. [CrossRef]

54. Lee, S.W.; Sung, H.J.; Jeon, H.M. Determinants of Continuous Intention on Food Delivery Apps: Extending UTAUT2 with Information Quality. Sustainability 2019, 11, 3141. [CrossRef]

55. Sukumaran, T. Coronavirus: Malaysia's Food Delivery Workers Help Nation Stay Connected amid Lockdown, South China Morning Post. 2020. Available online: https://www.scmp.com/week-asia/health-environment/article/3077719/coro-navirusdelivery-workers-keep-malaysia-connected (accessed on 8 September 2021).

56. Chiu, C.-M.; Wang, E.T. Understanding Web-based learning continuance intention: The role of subjective task value. Inf. Manag. 2008, 45, 194-201. [CrossRef]

57. Zhang, D.; Huang, G.; Yin, X.; Gong, Q. Residents' Waste Separation Behaviors at the Source: Using SEM with the Theory of Planned Behavior in Guangzhou, China. Int. J. Environ. Res. Public Health 2015, 12, 9475-9491. [CrossRef] [PubMed] 
58. Nguyen, T.H.; Vu, D.C. Food delivery service during social distancing: Proactively preventing or potentially spreading COVID-19? Disaster Med. Public Health Prep. 2020, 14, e9-e10. [CrossRef] [PubMed]

59. Fleming, K.; Thorson, E.; Zhang, Y. Going beyond Exposure to Local News Media: An Information-Processing Examination of Public Perceptions of Food Safety. J. Health Commun. 2006, 11, 789-806. [CrossRef]

60. Hong, C.; Choi, H.H.; Choi, E.-K.C.; Joung, H.-W.D. Factors affecting customer intention to use online food delivery services before and during the COVID-19 pandemic. J. Hosp. Tour. Manag. 2021, 48, 509-518. [CrossRef]

61. Shim, M.; You, M. Cognitive and affective risk perceptions toward food safety outbreaks: Mediating the relation between news use and food consumption intention. Asian J. Commun. 2015, 25, 48-64. [CrossRef]

62. Roh, M.; Park, K. Adoption of $\mathrm{O} 2 \mathrm{O}$ food delivery services in South Korea: The moderating role of moral obligation in meal preparation. Int. J. Inf. Manag. 2019, 47, 262-273. [CrossRef]

63. Wessells, C.R.; Anderson, J.G. Consumer Willingness to Pay for Seafood Safety Assurances. J. Consum. Aff. 1995, $29,85-107$. [CrossRef]

64. Zhao, Y.; Bacao, F. What factors determining customer continuingly using food delivery apps during 2019 novel coronavirus pandemic period? Int. J. Hosp. Manag. 2020, 91, 102683. [CrossRef] [PubMed]

65. Rodríguez-Ardura, I.; Meseguer-Artola, A. E-learning continuance: The impact of interactivity and the mediating role of imagery, presence and flow. Inf. Manag. 2016, 53, 504-516. [CrossRef]

66. McDonald, H.; Adam, S. A comparison of online and postal data collection methods in marketing research. Mark. Intell. Plan. 2003, 21, 85-95. [CrossRef]

67. Temkin, N. Engage Gen Y Online with Social Interactivity; Forrester: Cambridge, MA, USA, 2009.

68. Buschle, C.; Reiter, H.; Bethmann, A. The qualitative pretest interview for questionnaire development: Outline of programme and practice. Qual. Quant. 2021,1-20. [CrossRef]

69. Auad, L.I.; Ginani, V.C.; Leandro, E.D.S.; Stedefeldt, E.; Nunes, A.C.S.; Nakano, E.Y.; Zandonadi, R.P. Brazilian Food Truck Consumers' Profile, Choices, Preferences, and Food Safety Importance Perception. Nutrients 2019, 11, 1175. [CrossRef] [PubMed]

70. Liang, A.R.-D.; Lim, W.M. Exploring the online buying behavior of specialty food shoppers. Int. J. Hosp. Manag. 2011, 30, 855-865. [CrossRef]

71. Adam, D. The Effects of Physical Isolation on the Pandemic Quantified. 2020. Available online: https://www.the-scientist.com/ news-opinion/the-effects-of-physical-isolation-on-the-pandemic-quantified-67407 (accessed on 5 October 2021).

72. Hair, J.F.; Tatham, R.L.; Anderson, R.E.; Black, W. Multivariate Data Analysis, 5th ed.; Prentice-Hall, Inc.: Englewood Cliffs, NJ, USA, 1998.

73. Taber, K.S. The Use of Cronbach's Alpha When Developing and Reporting Research Instruments in Science Education. Res. Sci. Educ. 2018, 48, 1273-1296. [CrossRef]

74. Nunnally, J.C. Psychometric Theory, 2nd ed.; McGraw-Hill: New York, NY, USA, 1978.

75. Brown, T.A. Confirmatory Factor Analysis for Applied Research; Guilford Publications: New York, NY, USA, 2015.

76. Mustafa, M.B.; Nordin, M.B.; Razzaq, A.B.A. Structural Equation Modelling Using AMOS: Confirmatory Factor Analysis for Taskload of Special Education Integration Program Teachers. Univers. J. Educ. Res. 2020, 8, 127-133. [CrossRef]

77. Hair, J.F.; Money, A.H.; Samouel, P.; Page, M. Research Methods for Business; John Wiley and Sons: Chichester, UK, 2007.

78. Hair, J.F.; Black, W.C.; Babin, B.J.; Anderson, R.E.; Tatham, R.L. Multivariate Data Analysis, 6th ed.; Prentice-Hall: Upper Saddle River, NJ, USA, 2010.

79. Fornell, C.D.; Lacker, D.F. Evaluating Structural Equation models with Unobservable Variables and Measurement Error. J. Mark. Res. 1981, 18, 39-50. [CrossRef]

80. Bagozzi, R.P.; Yi, Y. On the evaluation of structural equation models. J. Acad. Mark. Sci. 1988, 16, 74-94. [CrossRef]

81. Kayes, K. Ordering Food during COVID-19: Crave or Cave? 2020. Available online: https:/ /www.dhakatribune.com/magazine/ avenue-t/2020/07/02/ordering-food-during-covid-19-crave-or-cave (accessed on 11 September 2021).

82. Vries, H.D.; Mudde, A.N. Predicting stage transitions for smoking cessation applying the attitude-social influence-efficacy model. Psychol. Health 1998, 13, 369-385. [CrossRef] 